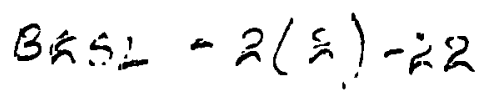

Built-Environment-Sri lanka -Vol. 02 Issue02:2002

\title{
Indoor thermal comfort in contemporary Sri Lankan urban houses: a simulation study
}

\author{
Rohinton Emmanuel \& \\ Gishan Rathnayake
}

\begin{abstract}
In this study, we estimate the prevalent thermal comfort regime in three of the most common contemporary urban house types in the Colombo Metropolitan Region (CMR). Using a parametric building energy simulation software, the study simulates the indoor Operative Temperature that would result from five passive design options to determine their potential to improve the indoor comfort levels. The simulation results show that passive strategies are no longer able to bring about adequate levels of thermal comfort. Strategies for modest improvements in the indoor bio-climate in contemporary Sri Lankan urban houses are proposed.
\end{abstract}

\section{Introduction}

Contemporary urban housing in Sri Lanka differs from traditional practice in several ways. Prominerit among them is the land area allocated to each housing unit. In the face of rapid urbanization, the plot size for urban housing has dwindled to a mere $150 \mathrm{~m}^{2}$ (6 perches) in the Colombo Metropolitan Region. Such small plots creates an urban geometry conducive to the trapping of solar radiation and therefore leads to increasing levels of thermal discomfort.

The problem of thermal discomfort in urban areas is compounded by the changing urban climate in the major cities. For example, there is evidence to suggest that air temperature in the CMR is rapidly increasing (Emmanuel, 1999) (See Figure 1). Changes to the urban microclimate demands that the conventional approaches to human comfort be looked afresh.

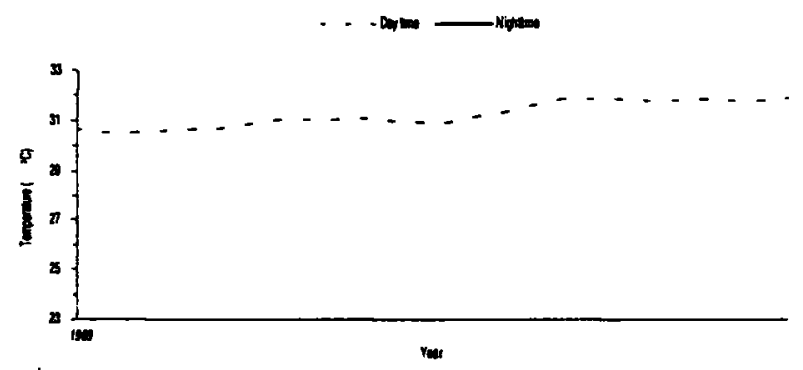

Figure 1: Max. \& Min. tempertaure trends in Colombo

However, architects in Sri Lanka continue to place their trust on natural ventilation as a panacea for thermal comfort. While such a strategy might have worked at an earlier time when plot sizes were large and building materials were generally organic, the changing urban climate coupled with the contemporary building practices lead one to suspect that the achievement of thermal comfort by passive design strategies is fast becoming impossible.
In this study, we simulate the thermal comfort conditions of three of the most commonly found contemporary urban houses in Sri Lanka, using a computer-aided parametric energy simulation software. The study determines the existing indoor Operative Temperature levels of the selected house forms and analyses the thermal comfort effects of five design options to determine their potential, if any, to improve the indoor comfort levels.

\section{Background}

\subsection{Thermal comfort \& building form}

Bio-climate of humans depend on four environmental variables and two "subjective" variables (Fanger, 1970). The environmental variables affecting thermal comfort are; Air Temperature, Relative Humidity, Air Velocity and Mean Radiant Temperature. Clothing and activity levels are the "subjective" variables that impinge upon human comfort.

The climatic variables mentioned above could be modified by certain building features. In this section we consider the following:
i. Building form;
ii. Space between buildings;
iii. Ceiling height

From a heat gain point of view, the building envelope area exposed to solar radiation is more important than the total surface area. In low latitudes, the roof is the building envelope surface most exposed to solar radiation, followed by the east and west walls. At night, the roof will lose most of the heat by radiation and therefore plays an important part in achieving noctumal comfort. Another important aspect of building form is the depth, or the distance between opposing facades. Where good internal air flow is required, dwellings should be shallow 
with 'single banked' rooms, so that each room has openings on two facades. Where air movement is seldom necessary, and where high volume-to-surface ratios are required, dwellings with 'double banked' rooms can be used to achieve buildings with greater depth.

The proportions of the space between buildings will determine the quantity and the quality of light falling onto the facades, as well as the availability of breeze, with wider spaces permitting increased illumination and better air movement. The proportions will also affect the amount of sun falling on the facades. The proportion of the space between buildings can be defined in terms of the spacing angle (the so-called "Light Angle"). The angle required to achieve a certain standard of lighting will vary according to the sky luminance, which tends to increase in lower latitudes. The spacing of buildings required for breeze can also be expressed in terms of the same angle, as can the spacing needed to permit or prevent solar radiation falling on walls (Evans, 1990).

Traditionally, higher ceilings are the norm in hot climates on account of the fact that such ceilings transmit less radiation to the occupants, since the solid angle of the ceiling subtended by the occupant would be smaller for higher ceilings. Additionally, the convective heat transfer would have less effect with higher ceilings, since the heated air would take longer to reach the occupants. Rooms with high ceiling heights would also have larger surface areas. Therefore, any surface heat gain would result in a smaller rise in temperature spread over a large area, rather than a large rise on a smallei surface.

Furthermore, the possibility of having greater differences in height between two openings improves the chances of creating a stack effect. Additionally, high ceilings increase the volume of air within the room, therefore ventilation rates can be reduced when outdoor temperatures are high, as the larger volume of air will not become 'stale' so quickly (Evans, 1990).

However, empirical evidence on the effect of high ceilings, double vs. single banked rooms and building forms often give conflicting results in the low tropics. It is therefore necessary to verify the comfort effects of these and other building variables as well as quantify the actual effect.

\subsection{Urbanization in the CMR}

Urbanization in Sri Lanka is a relatively new phenomenon. After attaining independence from the British rule in 1948, Sri Lanka had experienced a moderate population growth for a long period, but the growth rate. in urban population has intensified recently. The share of urban population has grown from $22 \%$ of the national population in 1981 to over $34 \%$ in 1993(CMRSP 1998). Over three quarters of urban population in Sri Lanka lives in the Colombo Metropolitan Region (CMR), which is home to roughly a quarter of all Sri Lankans. Due to the economic and administrative importance, the CMR is expected to grow rapidly in the coming years. By year 2010 , an expected 6.5 million people will be living in the CMR. Thus, the population density of the CMR would increase from 180 persons per hectare to 709 perśons per hectare in 2010 (CMRSP., 1998). Residential population density in the CMR was 35 persons per $\mathrm{Ha}$. in 1994 and is expected to increase to 85 persons per $\mathrm{Ha}$. by 2010 , while in the city of Colombo, it is expected to reach 117 persons per Ha (CMRSP, 1998).

Not surprisingly, the built up area in the region is growing rapidly (over $50 \%$ of the Colombo is hard land cover Emmanuel, 2000). However, the build-able area in Colombo is limited on account of the fact that the city is bounded by an ocean in the west and wetlands in the east. This has resulted in high demand for build-able land which in turn has resulted in greater land fragmentation. The current average plot size in the city of Colombo, stands at a mere $150 \mathrm{~m}^{2}$ (ct. Statistical Abstracts, 2000).

\subsection{House forms in the CMR}

Within this context, housing in the CMR has taken a peculiar form. The approach to urban housing has changed from expansive bungalows with lush green gardens to one of compactness and postage stampsized greenery.

The land restrictions, coupled with uniform building regulations have now resulted in similar housing solutions in the urban areas. Even a cursory glance through the variety of contemporary houses in Colombo and its suburbs would suggest that the apparently maddening array of house forms could be reduced to one of the following 6 types:

\section{Rectangular shaped house;}

2. ' $L$ ' - shaped house;

3. 'T' - shaped house;

4. 'U' - shaped house;

5. Center court type;

6. Irregular shaped.

\section{Method}

It is in this context that the present study explores the existing indoor thermal comfort in the most common house forms in the CMR. It then estimates the possible thermal comfort effects of five design options upon the current comfort levels.

A visual survey of the house forms in the CMR indicated. that among the contemporary house forms identified earlier, three house forms were the most prevalent:

i. Rectangular form (Type 1);

ii. 'L' Shaped house (Type 2);

iii 'Center courtyard house (Type 3) (Figure 2).

Therefore we simulated these three forms and design one "typical" house to represent each of the house forms according to the current Sri Lankan building code. Each house has an average floor area of $180 \mathrm{~m}^{2}$ and a plot size of $150-200 \mathrm{~m}^{2}$. 


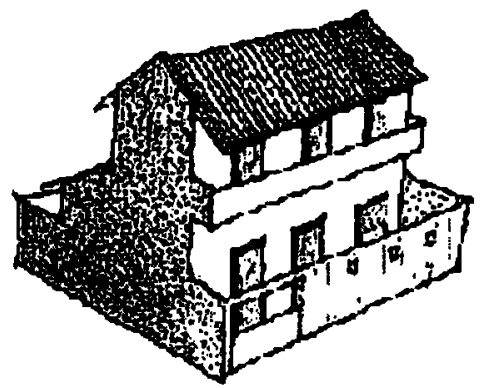

House Type 1 (Rectangular house)

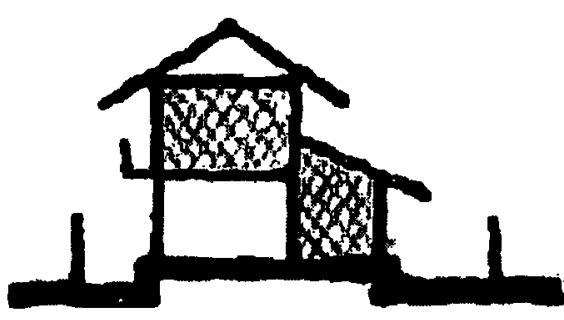

Section ( study areas are highlited)

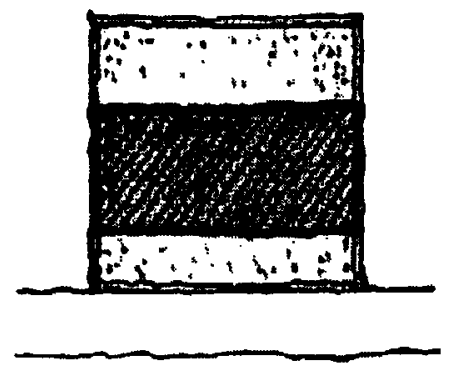

Site Layout

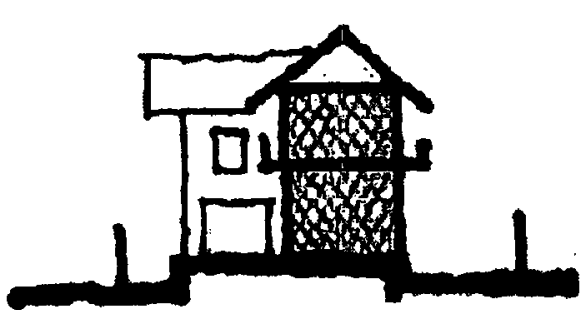

Section ( study areas are highlited)
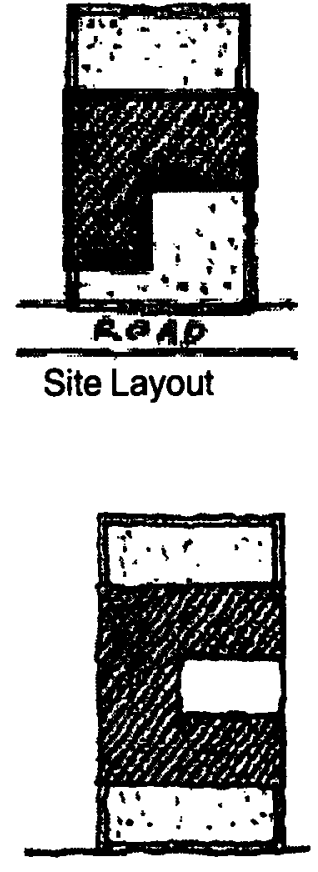

Site Layout

Site Layout

House Type 3 ( centre courtyard house)

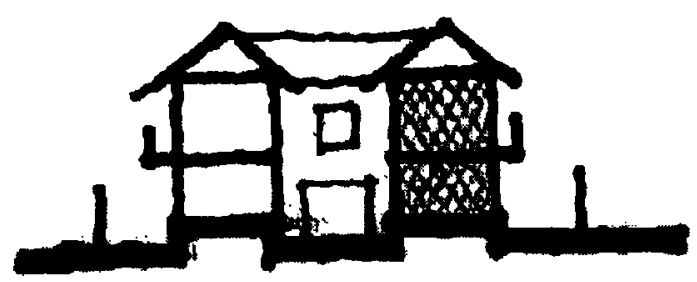

Section ( study areas are highlited)
Figure 2: House forms selected for study
The existing comfort conditions are estimated for each of the three house types during the hottest pre-monsoon month of April. Calculations of thermal comfort are presented for a Living room in the ground floor and a Bedroom in the upper floor.

The other significant features common to the three house models are given below:

i. Orientation - Major axis east/west;

ii. Internal partitions - ignored;

iii. Boundary walls $-2.1 \mathrm{~m}$ high, $225 \mathrm{~mm}$ thick burnt clay brick wall, cement : sand plaster on both sides;

iN. Walls - $225 \mathrm{~mm}$ thick brick walls, plastered both sides; v. Root $-22^{\circ}$ slope, Corrugated asbestos cement roof with flat asbestos sheet ceiling (a) 3m AFF;

v. Fenestration $-6 \mathrm{~mm}$ thick single glazed windows on wood frames with minimal opening on the east/west facade;

vi. Floor - Cement rendered on $100 \mathrm{~mm}$ mass concrete base.

Using a computer simulation program (Dynamic Energy Simulation Of Building - DEROB) eight alternates to the base case are created in the following manner:

1. Orientation (primary axis north/south;

$2-3$. Roof angle ( $30^{\circ} \&$ Flat roof); 
4. Parapet wall height $(3 \mathrm{~m})$;

5. Floor to ceiling height $(5 \mathrm{~m})$;

6-8.Wall material (CMU, Composite wall \& Compressed Earth Wall).

The operative temperature for each of the above eight variations for each of the three houses are simulated using DEROB software and the "best case" is selected for further analysis.

The input data used for the computer simulation are as follows:

i. Clothing levels of occupants -0.3 to $0.5 \mathrm{clo}$. units;

ii. Activity - general household activities, with an average metabolic rate of 1.0 met.

iii. Climatic Data - Thirty year average data for Colombo, (Lat. $=6.9^{\circ} \mathrm{N}$, Long. $=79.87^{\circ} \mathrm{E}$, Alt $=7.3 \mathrm{~m}$ ) in April.

\section{Results}

Figure 3a shows the variation of Operative Temperature (OT) level in the ground floor of the three house types during a typical April day. Figure $3 b$ shows the same for an upper floor room.

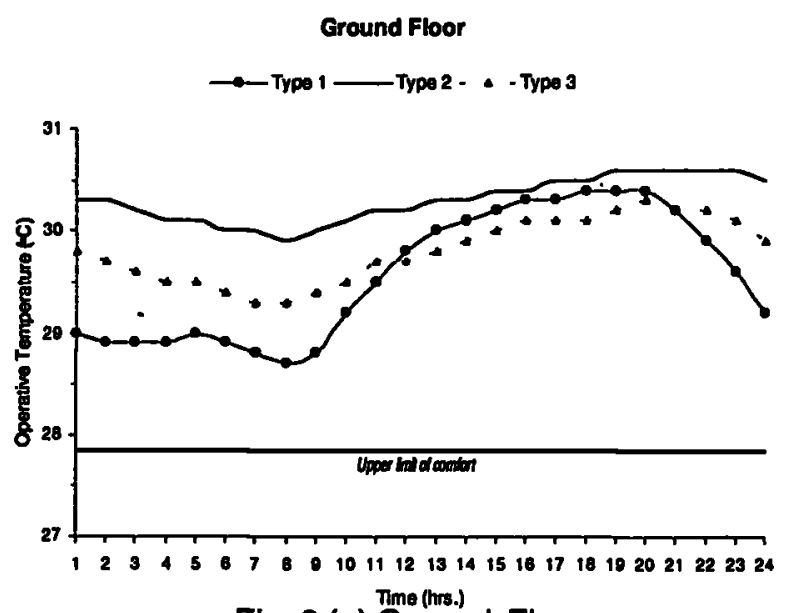

Fig. 3 (a) Ground Floor

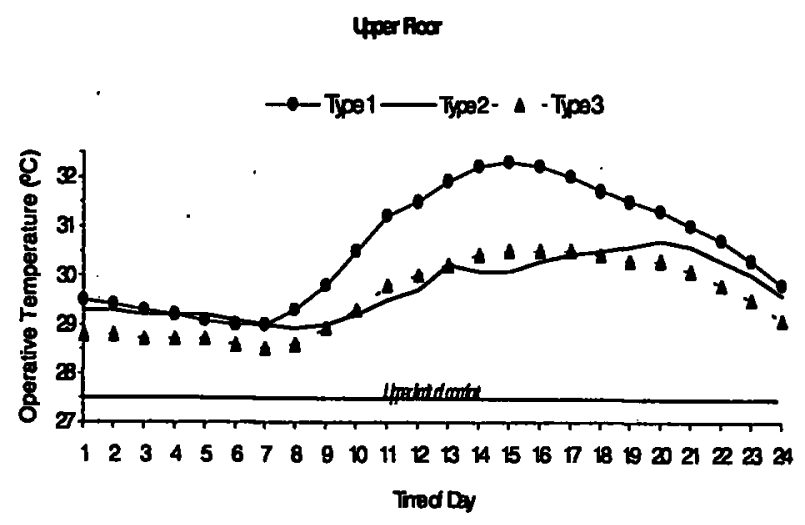

Fig. 3 (b) Upper Floor

Fig 3: Operating Temperature variations in the exsisting situations
Figure $3 a$ indicates that House Type 1 has an Operative Temperature (OT) level above $28.75^{\circ} \mathrm{C}$, which is almost $1^{\circ} \mathrm{C}$ above than the upper limit of standard comfort conditions.

Figure $3 b$ shows that during the daytime upper floor temperature increases at a higher rate than the ground floor and reach to its maximum at 15:00 hours in the evening. Ground floor has a lower OT than the upper floor at all times and during 11:00 - 19:00 hours OT difference between the two floors is more than $1^{\circ} \mathrm{C}$. The ground floor starts to heat up from 9:00 hours and begins to cool down only after 20:00 hours. Upper floor starts to cool down after 15:00 hours and reaches the ground floor comfort level at 05:00 hours.

As for House Type 2, upper floor OT level is above $29^{\circ} \mathrm{C}$, while the ground floor is above $30^{\circ} \mathrm{C}$ range at all times. This is $1.5^{\circ} \mathrm{C}$ higher than the standard comfort level. Both the ground and upper floors heat up after 08:00 hours. Upper floor OT increases at a faster rate than the ground floor and matches the ground floor level within five hours, but after 20:00 hours, upper floor starts to cool down rapidly while ground floor remains over the $30^{\circ} \mathrm{C}$ range. From midnight to $10: 00$ hours the OT difference between the two floors is approximately $1^{\circ} \mathrm{C}$. House Type 3 too, shows an OT over $28.5^{\circ} \mathrm{C}$, which is $.1^{\circ} \mathrm{C}$ higher than the standard comfort level. The ground OT remains above $29.25^{\circ} \mathrm{C}$ at all times. The patterns of change in OT is similar to House Type 2.

When considering the ground floor alone, house type 2 shows the highest OT level during the 24 hours and the simplest form, house type 1, shows the lowest OT levels. The difference between the highest and the lowest values is approximately $1^{\circ} \mathrm{C}$.

House type 1 heats up at a higher rate than the other two types during the daytime and matches the maximum temperature levels of other to types, but after 20:00 hours it cools down at a rapid rate and reaches its minimum levels in the early morning hours. It is interesting to note that the diurnal differences in the " $\mathrm{L}^{n}$ shape and center court houses are considerably smaller than house type 1.

Operative Temperature levels of upper floors presents a different picture from the situation of ground floors. In the upper floor, house type 1, (rectangular form) indicates the highest value during the daytime. The most probable reason would be the one room thick width of the upper floor of the house type 1. In the other two types, one volume of the upper floor is always shaded by another at the same floor. Therefore in restricted urban situations where the adequate air flow through the house is not practicable, double banked could be effectively used to improve indoor comfort conditions during the day. This is contrary to the conventional wisdom with regard to single and double bank rooms. ("Ideally dwellings should be one room thick with windows on both side of the building..." Evans, 1990) .

When considering both the ground and upper floors, house type 2 ("L" shaped form) could be identified as the most uncomforiable type. Compared to the others two 
types it has a smaller variation in OT which never goes below $29^{\circ} \mathrm{C}$, (this is $1.5^{\circ} \mathrm{C}$ higher than the upper limit of thermal comfort).

\subsection{Effects of Design Options}

Table 1 summarizes the average OT differences due to the eight design options considered for the ground floor as well as the upper floor. The differences are given as Design Option minus Base Case. Thus, a negative difference indicates that the design option is cooler than the base case and therefore is welcome. effect of parapet wall on ground floor areas. Parapet walls would reduce the direct solar radiation impinging on external wall surfaces of a building in restricted urban situation. However, its effect on ventilation requires further study.

The indoor comfort effect of the three wall materials selected is virtually nil in all cases in the ground floor. Some improvement is seen in the upper floor of House Type 1, particularly with the use of CMU wall. Thus, CMU could be a cost-effective comfort enhancing alternative for the simple rectangular house type. Compressed earth wall on the hand, does not perform as well as expected.

\section{Table 1: Average operative Temperature differences fro the base case}

\begin{tabular}{|c|c|c|c|c|c|c|c|c|c|c|c|c|c|c|c|c|c|c|c|c|c|c|c|}
\hline \multicolumn{8}{|c|}{ Rectangular House } & \multicolumn{7}{|c|}{ 'L' Shaped House } & \multicolumn{9}{|c|}{ Centre Courtyard House } \\
\hline 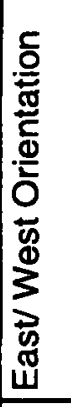 & 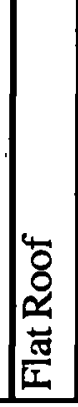 & 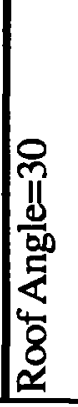 & 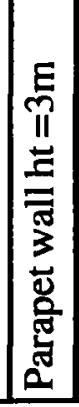 & 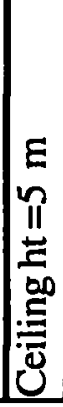 & 零 & 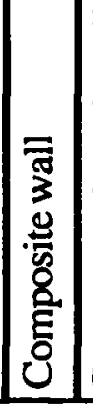 & 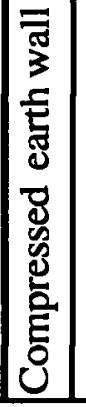 & 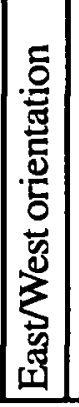 & 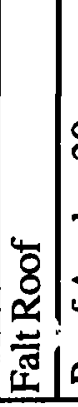 & $\begin{array}{l}0 \\
\mathbb{1 1} \\
\frac{0}{80} \\
\frac{8}{4} \\
4 \\
8 \\
\Sigma\end{array}$ & 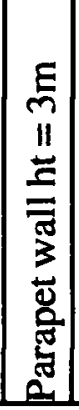 & 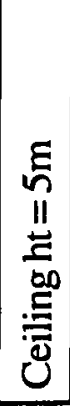 & 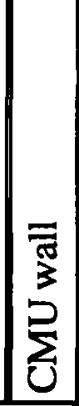 & 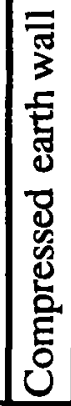 & 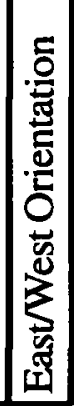 & 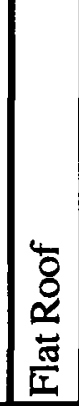 & 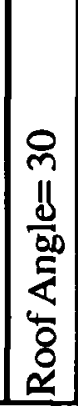 & 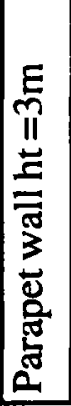 & 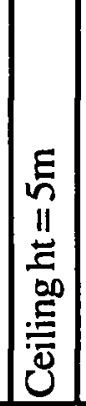 & 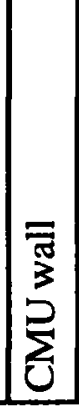 & 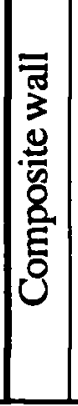 & 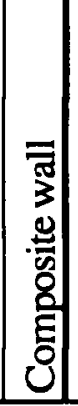 & 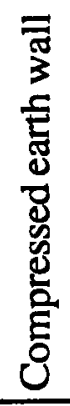 \\
\hline \multicolumn{24}{|c|}{ ND FLOOR } \\
\hline 1.1 & -0.5 & 0.0 & -0.5 & 0.0 & 0.2 & 0.1 & 0.0 & 0.5 & -0.1 & 0.0 & -0.3 & 0.0 & 0.0 & 0.0 & 0.0 & 0.7 & 0.1 & -0.1 & -0.2 & -0.2 & 0.1 & 0.0 & 0.0 \\
\hline 0.7 & 0.3 & 0.1 & -0.5 & 0.2 & 0.2 & -0.2 & 0.1 & $0.6-$ & \begin{tabular}{l|l}
-0.1 & 1 \\
\end{tabular} & 0.0 & -0.3 & 0.1 & 0.1 & -0.2 & 0.0 & 0.9 & 0.1 & 0.0 & -0.2 & 0.0 & 0.1 & 0.0 & 0.1 \\
\hline \multicolumn{24}{|c|}{ R FLOOR } \\
\hline-0.3 & -0.7 & -0.1 & -0.3 & -0.5 & -0. & $5-0.5$ & -0.3 & 1.0 & -0.3 & \begin{tabular}{l|l}
0.0 \\
\end{tabular} & -0.1 & 0.0 & 0.1 & & & 0.5 & 0.6 & -0.4 & -0.1 & -0.7 & 0.1 & 0.2 & 0.0 \\
\hline 0.0 & 0.9 & -0.1 & -0.3 & 0.3 & -0.4 & -0.1 & -0.1 & 0.6 & 0.5 & 0.1 & -0.1 & 0.3 & 0.0 & 0.4 & & \begin{tabular}{l|l}
0.7 & 0 \\
\end{tabular} & 0.9 & \begin{tabular}{l|l}
0.0 \\
\end{tabular} & \begin{tabular}{l|l|}
0.0 \\
\end{tabular} & \begin{tabular}{l|l} 
\\
\end{tabular} & 0.2 & -0.1 & 0.2 \\
\hline
\end{tabular}

Note: a.m. $=0900-1759$ hrs; p.m.1900-0559 hrs (next day)

One of the striking features of this comparison is that none of the selected design options are able to improve the indoor comfort level to reach the upper limit of Thermal Comfort $\left(27.5^{\circ} \mathrm{C}\right)$ during the hottest month.

A change to flat roof would bring some relief during the daytime (up to $0.7^{\circ} \mathrm{C}$ cooler), but large negative effects are also seen at night, particularly in the upper floor $\left(0.9^{\circ} \mathrm{C}\right.$ warmer). This is especially the case for House Types 1 and 3 . The change of roof angle from $22^{\circ}$ to $30^{\circ}$ has little or no effect on indoor comfort. A small improvement $\left(0.4^{\circ} \mathrm{C}\right)$ occurs in the upper floor of House Type 3 during the day, but its cooling effects are negligible.

A $2 \mathrm{~m}$ increase in ceiling height produces some improvement to the upper floor comfort during the day in House Types 1 \& 3, but the effects are almost negated at night.

Contrary to popular belief, an increase in boundary wall height from $2 \mathrm{~m}$ to $3 \mathrm{~m}$ actually improves the indoor comfort conditions in all cases. The effect is particularly striking in the case of ground floor area of House Type 1 during the day. A possible reason could be the shading
The only consistently significant change in indoor comfort occurs when the orientation of the house is changed from north/south to east/west. In all cases, an east/ west oriented house produces consistently warmer indoor conditions. Conversely, a north/south oriented building would be cooler, but the degree of improvement is not adequate to bring the indoor comfort conditions within the accepted limits of thermal comfort.

From the above, it is clear that most of the selected design options have no significant influence in lowering the indoor operative temperature to reach the upper margin of standard thermal comfort levels.

It is interesting to note that house type 1, which is the simplest form among three types studied, has a lot of flexibility in reacting to the selected design options.

Based on the above, it appears that a north/south oriented house with higher parapet wall and higher floorto-ceiling height might perform better than the base case. The results of such an option is described below as the "best case" scenario. 


\subsection{Comparison of best design options}

Figure 4 shows the thermal comfort variation during the month of April between three basic house forms and three best cases, simulated based on the results of

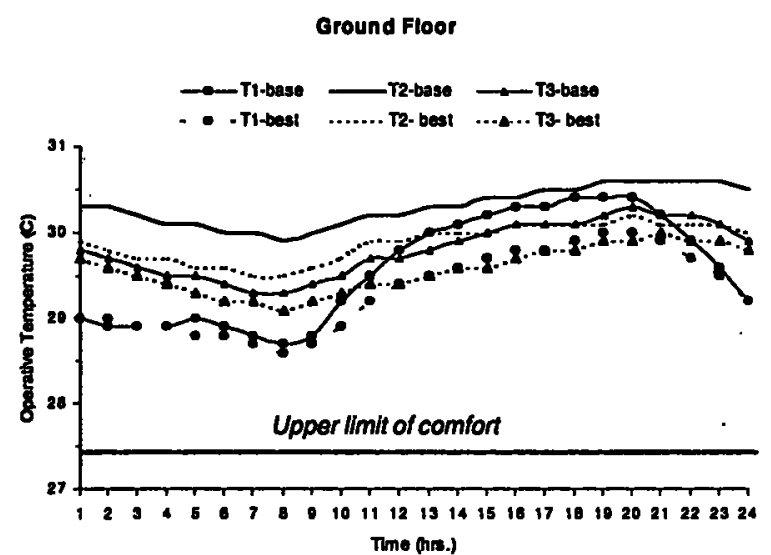

4 (a) Ground Floor

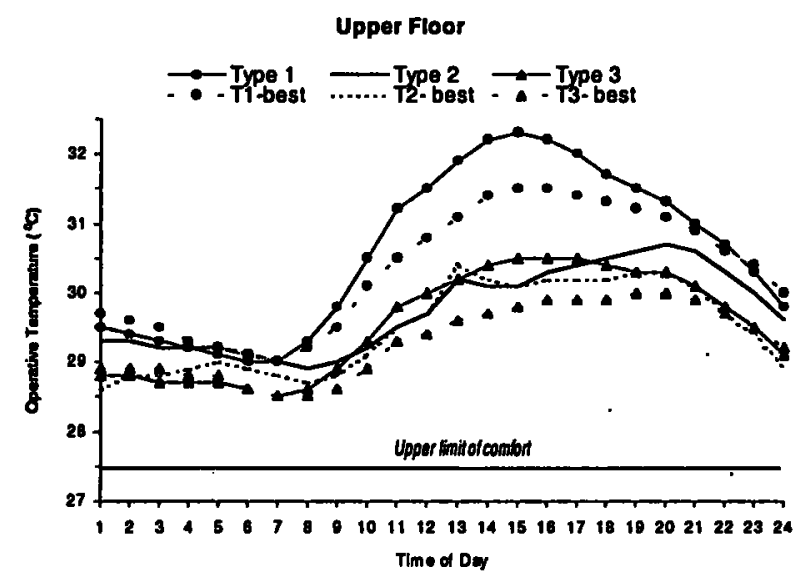

4 (b) Upper Floor

Figure 4: The base case vs. best case comparison

previous analysis. It indicates that even the combined design options were unable to sufficiently lower the indoor comfort levels to reach the upper limits of thermal comfort during the month of April. The best that could be achieved is an indoor OT of $28.5^{\circ} \mathrm{C}$, which is still $1.0^{\circ} \mathrm{C}$ above the comfort threshold.

In all three-house types the best-case scenario has resulted in considerably lower operative temperature in the ground floor, but the upper floor of house type 2 has not shown much improvement. The reason could be the particular shape of this house. Because of its 'L' shape, one wing of the building is always exposed to the east/ west sun.

When considering both ground and upper floors, house type 3 (center court yard type) could be identified as a better option among the three types.

But when considering the ground floor only, house type 1 (rectangular simple form), appears to be the best option. The simple rectangular form will be the best option if it could be built with double-bank rooms. This is of course against the norms of conventional wisdom and therefore needs to be studied further, perhaps with the aid of a more realistic airflow simulation tool.

\section{Conclusion}

The present study explored the variation of indoor thermal comfort levels of the most common urban residential forms prevalent in the Colombo region. Using a computer simulation technique, the study estimated the existing comfort situations as well as the effect of five design options (with 8 different possibilities).

Comparing the indoor comfort conditions of the existing as well as design altered situations with the international comfort norms, (e.g.: ISO 7730: 1994), it is clear that all three-house types were not comfortable during the month of April. None of the selected design options or even the best cases simulated were able to significantly improve the indoor thermal comfort.

Perhaps the only possibility is that minorimprovement could come from higher boundary walls (space) creating high open volumes between the house and the boundary. This could be a better solution in restricted urban situations where natural airflow to the house from neighboring sites is minimal in any case.

\section{References:}

Correa, C., (1999). Housing and Urbanisation, Bombay: The Urban design Research Institute.

Colombo Metropolitan Regional Structure Plan Colombo Metropolitan Regional Structure Plan (CMRSP), Vol. 1, (1998). Urban Development Authority, Colombo, Sri Lanka.

DEROB-LTH for MS Windows (1999), User Manual Version 99.01+3, Department of Building Science, Lund Institute of Technology, Sweden.

Emmanuel, R., (1999). Urban Heat Island \& Cooling Load: The case of an Equatorial City, Architecture, Energy \& Environment, 1999, 16:1 - 16:8.

Emmanuel, R.' (2000). Land cover and UHI correlations in the CMR, SRC Grant NO. 2000/01/02, University of Moratuwa.

Evans, M. (1990). House, Climate and Comfort. London: The Architectural Press.

Fanger, P.O., (1970). Thermal Comfort, Analysis and Application in Environmental Engineering Environmental Engineering, Copenhagen: Danish Technical Press.

Givoni, B., (1976). Man, Climate and Architecture, $2^{\text {nd }}$ edition, Essex: Applied Science.

ISO 7730, (1994). Moderate thermal environments Determination of the PMV and PPD indices and specification of the conditions for thermal comfort, $2^{\text {nd }}$ edition, 1994-12-15, Reference number ISO 7730:1994(E).

Statistical Abstracts 1999 - Sri Lanka, (2000), Department of Census and Statistics, Ministry of Finance and Planning, Sri Lanka. 